\title{
Design of 4x4 Banyan optical switch using optoelectronic MZI switches with low crosstalk
}

\author{
Vandana Sachdeva ${ }^{1}$, Rajeev Ratan ${ }^{2}$ and J. S. Mahanwal ${ }^{2}$ \\ ${ }^{1}$ ECE Deptt., D.C.T.M., Palwal, Haryana; ${ }^{2}$ E \& IE Deptt., Apeejay College of Engg., Sohna, Gurgaon, Haryana, India
} rajeevratanarora@gmail.com

\begin{abstract}
We introduce here a designing of $2 \times 2 \mathrm{MZI}$ (Mach-Zehnder Interferometer) optical switch. The switching of the optical signal is realized with the use of fast electro-optical effects. The designed model has a very high switching capability and is extremely reliable. Various design parameters have been varied to improve the performance of the switch. Then the basic $2 \times 2$ switch is exploited in design of $4 \times 4$ banyan switch. Banyan switch is a good candidate for further use in higher order switches. Simulation results are shown for $2 \times 2$ and $4 \times 4$ banyan architecture with low cross-talk values.
\end{abstract}

Keywords: Optical waveguides, MZI (Mach-Zehnder Interferometer), Banyan architecture, optical field.

Introduction

Electro-optic effect is a change in refractive index of the material with the variation of intensity of an electric field applied to it; this is the linear electro-optic effect. Speed of this effect is less than 1 ns. Lithium Niobate $\left(\mathrm{LiNbO}_{3}\right)$, Polymers, Lead zirconate titanate (PZT and GaAs-AIGaAs (Martin Nord, 2002) are the materials used in designing of switches with electroopto effects. $\mathrm{LiNbO}_{3}$ is based on its large electro- opto coefficient (Ron A. Spanke, 1986). Directional couplers in $\mathrm{Ti}: \mathrm{LiNbO}_{3}$, have been under research for over a decade and recent progress has resulted in $8 \times 8$ arrays of switches being offered commercially (Erickson, 1989). Interferometric switches are based on Mach-Zehnder Interferometers (Lai et al., 1998) shown in Fig.1, which consists of a $3 \mathrm{~dB}$ splitter and a $3 \mathrm{~dB}$ combiner, connected by two interferometer arms. By changing the effective refractive index of one of the arms, the phase difference at the beginning of the combiner can be changed such that the light switches from one output port to the other. 3-dB couplers were chosen to be multi-mode interference (MMI) couplers due to their polarization independence, fabricationand wavelength tolerance. $A$ 2x2 MMI switch with Banyan architecture with coupling loss of $5.38 \%$. and the crosstalk of $6.99 \times 10^{-05}$ has already been analyzed (Singh et al., 2008).

\begin{tabular}{|c|c|c|}
\hline $\begin{array}{c}\text { Substrate- } \\
\text { LiNbO }_{3}\end{array}$ & $\begin{array}{c}\text { Pable I. Wafer properties } \\
\text { direction-Y, } \\
\text { crystal cut-Z }\end{array}$ & $\begin{array}{c}\text { Thickness } \\
10 \text { micrometers }\end{array}$ \\
\hline \multicolumn{3}{|c|}{ Wafer Properties } \\
\hline Wafer Profile- $^{2}$ Wafer dimensions \\
\hline LiNbO $_{3}$ & Length-33 mms & Width-0.1 mms \\
\hline \multicolumn{3}{|c|}{ 2 D Wafer Properties } \\
\hline Material & Thickness & Refractive index \\
\hline Air/Cladding & 2 micrometers & 1 \\
\hline
\end{tabular}

\section{Designing of $2 \times 2$ basic MZI switch}

The wafer is a planar substrate on which we design devices. Its length is along Z-axis, horizontal on the screen and width is along $X$-axis, vertical on the screen. Thickness of the substrate is in y-direction, perpendicular to the screen and not shown on the layout interface. MZI switch is created on a z-cut wafer of Lithium Niobate and is surrounded by air cladding. Wafer is designed with $33 \mathrm{mms}$ of length, 10 micrometers of thickness and 0.1 mms of width (Table 1). The device is oriented along the Y-optical axis of the Lithium Niobate. We need to define a diffused material for the substrate and a dielectric material for cladding. Air is the di-electric material for cladding and its thickness is 2 micrometers. Titanium diffused waveguides in lithium Niobate are formed by the diffusion of titanium dopant into the lithium niobate host. To form a waveguide, a stripe of titanium with thickness before diffusion of .05 micrometers is deposited on the substrate. Waveguide has a width of 8.0 micrometers. S-Bend Sine and Linear waveguides are started by laying down these basic waveguide elements necessary for the construction of the switch. To provide electro-opto effects we used three electrode set with buffer layer on substrate. Buffer layer is introduced between electrodes and substrate to reduce the losses that are due to metallic cover of the waveguide. The buffer layer has thickness of 0.3 micrometers with horizontal and vertical permittivity of 4 micrometers. Electrodes are defined in three regions with different parameters. First region has electrode with width of 50 micrometers and zero voltage. Second and third electrodes have width of 26 micrometers and zero voltage. Gap between first and second electrode is 6 micrometers and between second and third electrode is 6 micrometers. Second electrode is placed with 5.5 micrometers of center position. Mode type input field which initializes the fundamental mode of a waveguide (Table 2) as the starting field has been selected at $Z=0$ position. The whole device is designed on layout designer of OPTIBPM tool of OPTIWAVE software. Fig. 2 shows basic $2 \times 2 \mathrm{MZI}$ switch. 
Indian Journal of Science and Technology

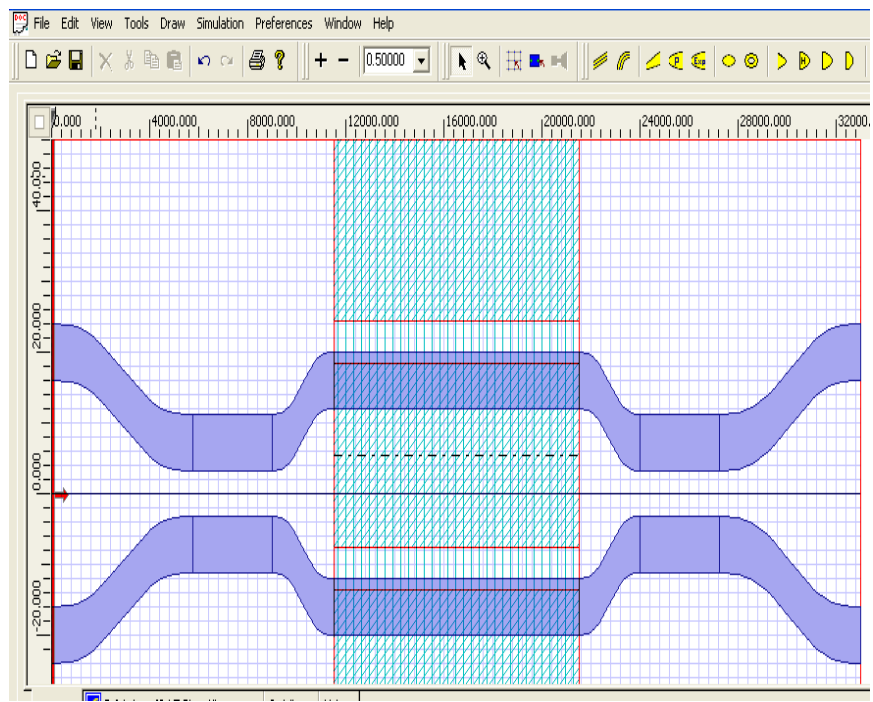

Fig.2. $2 \times 2 \mathrm{MZl}$ switch

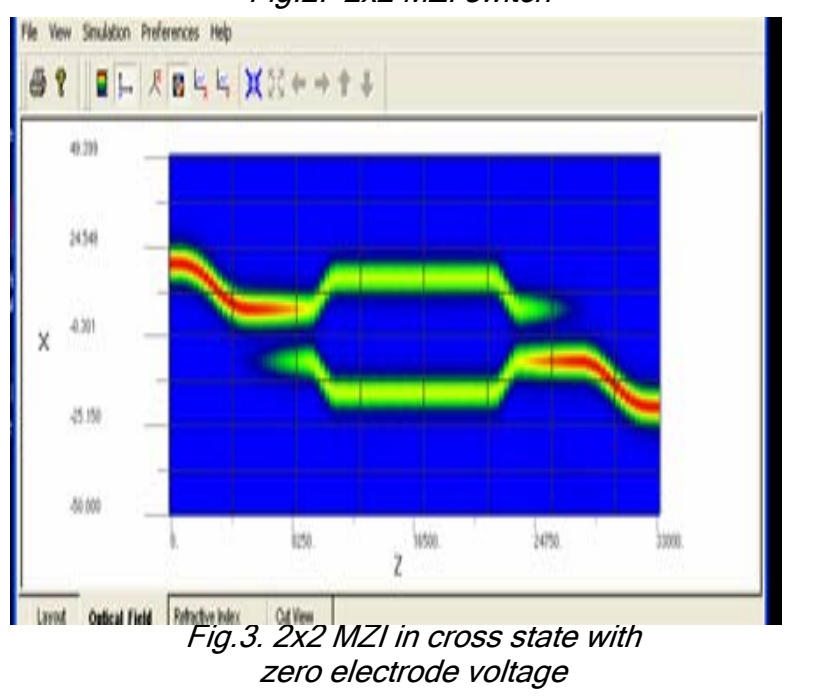

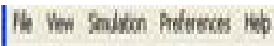

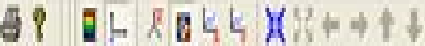

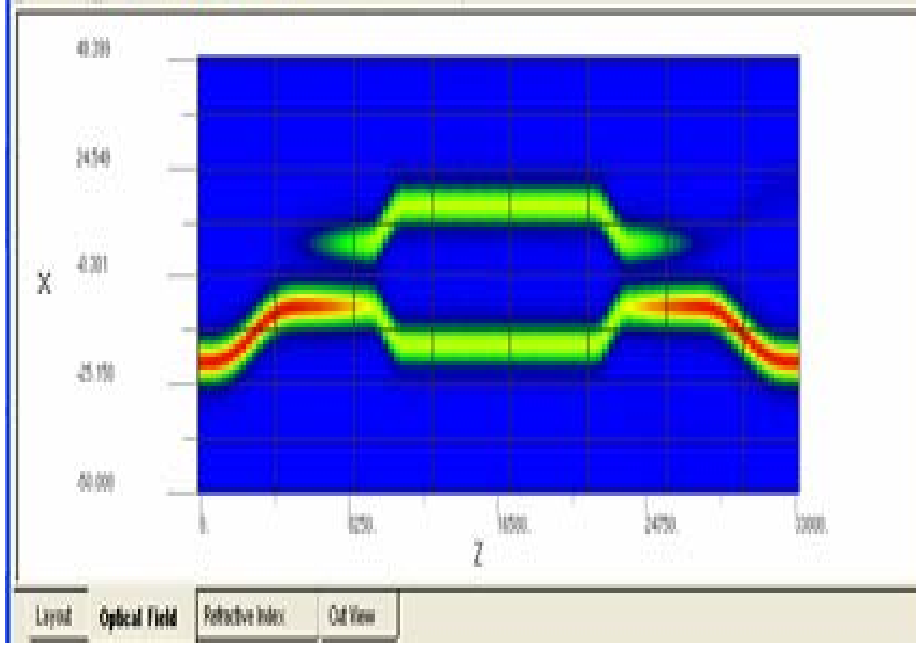

Fig.6. $2 \times 2 \mathrm{MZI}$ in bar state with 7.3 volts of electrode voltage

Research article

CIndian Society for Education and Environment (iSee)
"Optical switch" http://www.indjst.org
Vol.2 No. 10 (Oct 2009)

ISSN: 0974- 6846

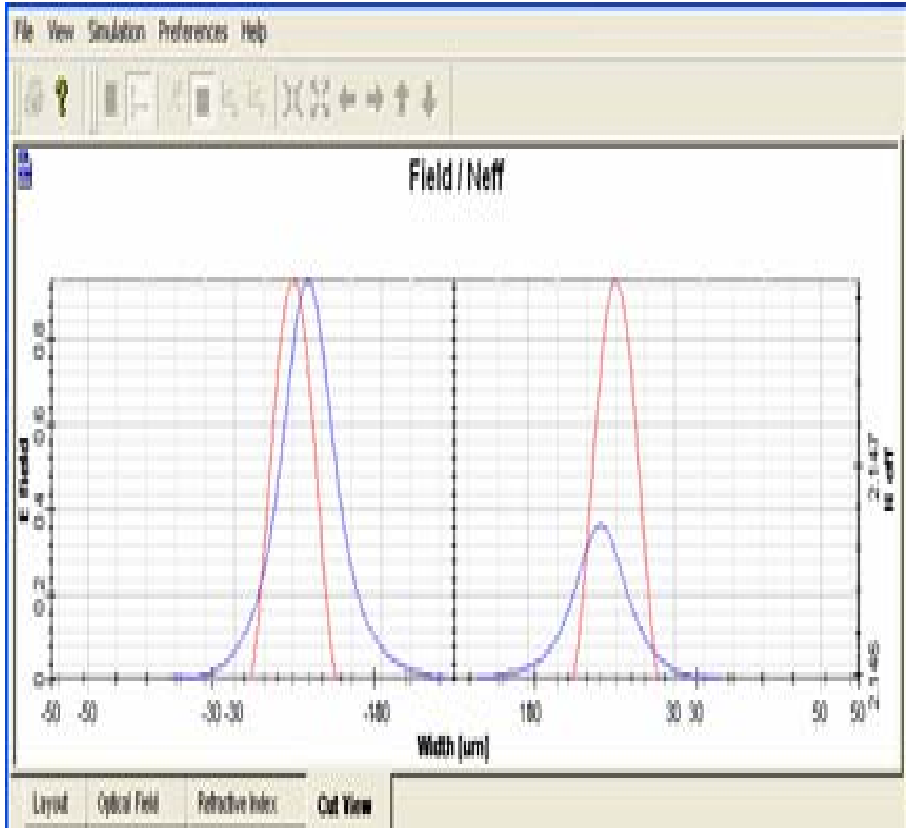

Fig.4. Optical field propagation in cross state

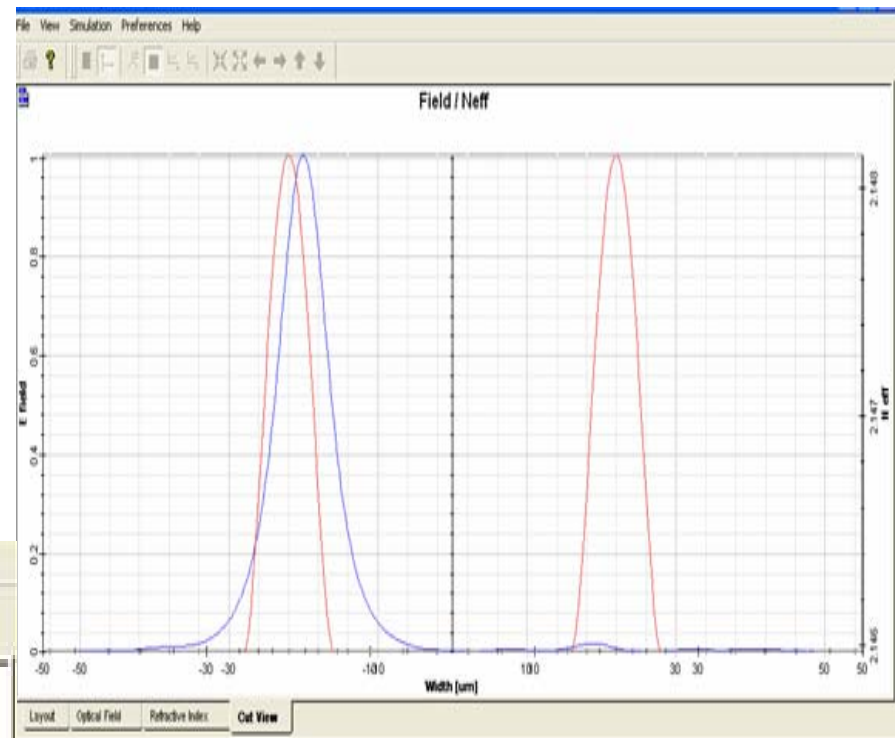

Fig.5. Optimized result of $M Z I$ in cross state for $D_{h}$ of 3.5 micrometers and $D_{v}$ of 3.7

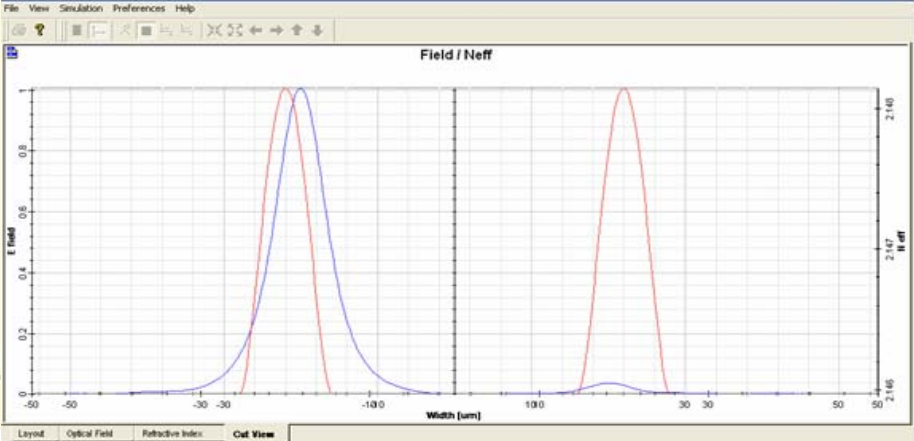

Fig. 7. Optical field propagation in bar state Indian J.Sci.Technol. 


\section{Simulation}

After the input plane has been defined the global data is set with refractive index MODAL. Wavelength selected for simulation is 1.3 micrometer. The $2 \mathrm{D}$ properties have been set with TM polarization and 500 mesh points. The simulation results could be sensitive to the number of mesh points. In general, the usage of more mesh points results in better precision. PARAXIAL BPM solver, FINITE DIFFE-RENCE engine is used. Finite Difference Taylor series expansions are used to derive finite-difference schemes to approximate the wave equations. BPM 2D provides TBC (Transparent Boundary Conditions) method to escape unwanted reflections from the boundaries. We did 2D isotropic calculation and observed switching results in Cross and bar states (Fig. 3-7).
Table 2. Waveguide properties

\begin{tabular}{c|c|c|}
$\begin{array}{c}\text { Stripe thickness } \\
\text { before diffusion }\end{array}$ & \multicolumn{2}{|c|}{.05 micrometers } \\
\hline Tl: $\mathrm{LiNbO}_{3}$ & $\mathrm{D}_{\mathrm{h}}$ & 4.0 \\
\cline { 2 - 3 } & $\mathrm{D}_{\mathrm{v}}$ & 3.5 \\
\hline
\end{tabular}

\section{Simulation of $2 \times 2$ Banyan network}

A 2x2 MZI network with Banyan architecture is realized and simulated in Optisystem of OPTIWAVE Software. Switches used in proposed architecture

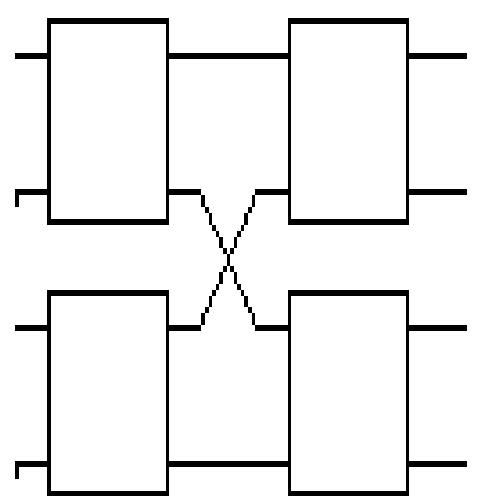

Fiq. 8. 4x4 Banyan architecture are in Bar state. A CW laser used as optical source is connected to first port of input by keeping other port at optical null. The basic parameters of optical source are frequency, linewidth and power. Fig. 9 shows this configuration with input power $=10 \mathrm{mw}$, line width $=10 \mathrm{MHZ}$ and results show that $9.89 \mathrm{mws}$ of power is obtained at bar state and 0.05 mws of power is obtained at cross port which is very small. Table 3 shows analysis of proposed set-up for different values of input power. Crosstalk value measured is $-22.9 \mathrm{db}$.

\section{Banyan Architecture}

A typical Banyan architecture contains $\log _{2} n$ stages each having $\mathrm{n} / 2,2 \times 2$ switches. In Banyan network there is unique path between input and output and the no. of switching elements in each path is fixed and equal to $\log _{2}$ $\mathrm{n}$. These characteristics have made banyan network very attractive for constructing switching networks with directional couplers because loss and attenuation of optical signal are proportional to no. of couplers that the optical signal crosses. Fig. 8 shows a typical $4 \times 4$ Banyan network with 4, 2x2 MZI switches.
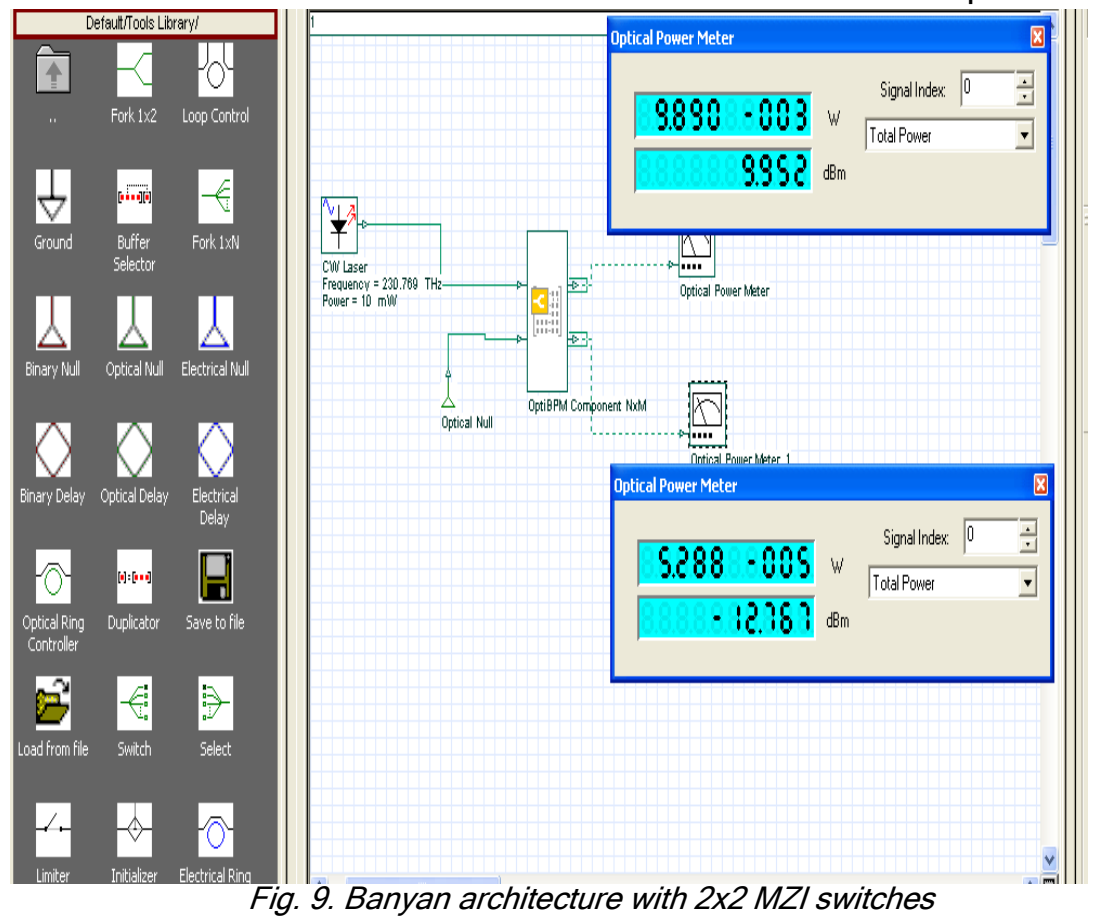

Fig. 9. Banyan architecture with $2 \times 2 \mathrm{MZI}$ switches

Research article

CIndian Society for Education and Environment (iSee) 4x4 Banyan network with 2x2 MZI switches (Table 4)

A $4 \times 4$ Banyan switch is designed using $4, \mathrm{MZI}$ binary $(2 \times 2)$ switches. Fig. 10 shows power inputs of $10 \mathrm{~mW}$ and 9.78 mws of power is obtained at first output port. Cross talk found for this set-up is $-22.7 \mathrm{db}$.

\section{Conclusion}

An optimum 2x2 Mach-Zehnder interferometer optical switch based on electro-opto effects has been successfully designed for switching optical signal with wavelength $1300 \mathrm{~nm}$. The coupling efficiency of the $2 \times 2$ optical switch designed in cross and bar state is optimized by changing the design parameters of the switch. A $2 \times 2 \mathrm{MZI}$ switch in bar state with Banyan architecture has been designed and realized in Optisystem also. Thus a newly developed $4 \times 4$ blocking banyan optical switch is designed which is having extremely low crosstalk of $-22.9-22.7 \mathrm{db}$. For future work It is recommend that the designing of $2 \times 2$ nonblocking banyan optical switch with lower losses can be done.Proposed $2 \times 2$ optical switch can also used for designing large switches using various architectures like Benes, Spanke-Benes, and Crossbar etc.

\section{References}

1.Erickson JR (1989) Guided wave optical switching. AT\&T Bell Laboratories, 200, Park Plaza, Naperville, IEEE 00983063/89/0200 0125

2. Lai Q, Hunziker W and Melchior H (1998) Low-Power compact 2x2 thermo-optic silica -on silica waveguide switch with fast response. IEEE Photon. Technol. Lett. 10
"Optical switch" http://www.indjst.org
Vandana Sachdeva et al. Indian J.Sci.Technol. 
Vol.2 No. 10 (Oct 2009)

ISSN: 0974- 6846
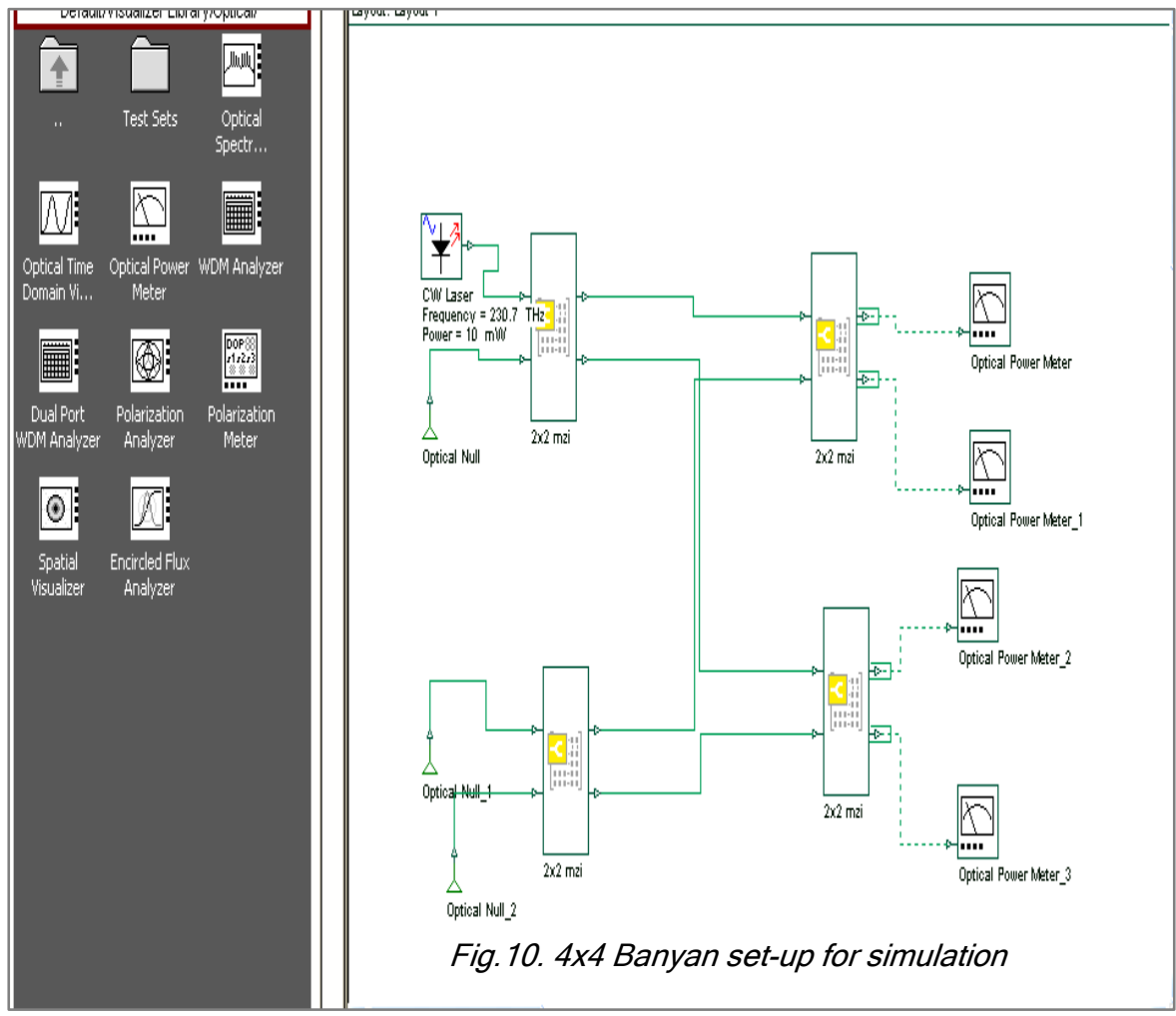

\begin{tabular}{|c|c|c|}
\hline \multicolumn{3}{|c|}{$\begin{array}{l}\text { Table 3. Analysis of } 2 \times 2 \text { set up for } \\
\text { different input powers }\end{array}$} \\
\hline $\begin{array}{l}\text { Input } \\
\text { power }\end{array}$ & $\begin{array}{l}\text { Output in } \\
\text { cross state }\end{array}$ & $\begin{array}{l}\text { Output in } \\
\text { bar state }\end{array}$ \\
\hline $20 \mathrm{mws}$ & $19.78 \mathrm{mws}$ & $0.1058 \mathrm{mws}$ \\
\hline $30 \mathrm{mws}$ & $29.67 \mathrm{mws}$ & $0.1506 \mathrm{mws}$ \\
\hline 40 mws & $39.56 \mathrm{mws}$ & $0.211 \mathrm{mws}$ \\
\hline \multicolumn{3}{|c|}{$\begin{array}{l}\text { Table 3. Analysis of } 2 \times 2 \text { set up for } \\
\text { different input powers }\end{array}$} \\
\hline $\begin{array}{l}\text { Input } \\
\text { power }\end{array}$ & $\begin{array}{l}\text { Output in } \\
\text { cross state }\end{array}$ & $\begin{array}{l}\text { Output in } \\
\text { bar state }\end{array}$ \\
\hline $20 \mathrm{mws}$ & $19.78 \mathrm{mws}$ & $0.1058 \mathrm{mws}$ \\
\hline $30 \mathrm{mws}$ & $29.67 \mathrm{mws}$ & $0.1506 \mathrm{mws}$ \\
\hline 40 mws & $39.56 \mathrm{mws}$ & $0.211 \mathrm{mws}$ \\
\hline
\end{tabular}

Table 4. Analysis of 4x4 Banyan set-up

\begin{tabular}{|c|c|c|c|}
\hline $\begin{array}{c}\text { Input } \\
\text { Port }\end{array}$ & $\begin{array}{c}\text { Input power } \\
\text { in mws }\end{array}$ & $\begin{array}{c}\text { Output power } \\
\text { in mws }\end{array}$ & $\begin{array}{c}\text { Output } \\
\text { port }\end{array}$ \\
\hline 1 & 10 & 9.78 & 1 \\
\hline 2 & Optical null & 0.052 & 2 \\
\hline 3 & Optical null & 0.052 & 3 \\
\hline 4 & Optical null & 0.0002 & 4 \\
\hline
\end{tabular}

(5), 681.

3. Martin Nord (2002) Optical switching technologies for optical-line, Burst and Packet switching, R \&DR 32.

4.Ron A. Spanke (1986) Architectures for large nonblocking optical space switches. IEEE J. Quantum Electr. Vol. QE-22, No: 6.

5.Singh G, Sharma MK, Vijay Janyani and Yadav RP (2008) Design of $4 \times 4$ banyan optical switch using MMI switches with low crosstalk \& low coupling loss, IEEE Proc. Intl. Conf. on Microwave-8, 978-1-4244-26904444/08 